\title{
Evaluation of Insecticide Resistance and Biochemical Mechanisms in a Population of Culex quinquefasciatus (Diptera: Culicidae) from São Paulo, Brazil
}

\author{
José Eduardo Bracco/ ${ }^{+}$, José Maria S Barata*, Osvaldo Marinotti**
}

\begin{abstract}
Laboratório de Bioquímica e Biologia Molecular de Vetores, Superintendência de Controle de Endemias do Estado de São Paulo (Sucen), Rua Paula Souza 166, 01027-000 São Paulo, SP, Brasil *Faculdade de Saúde Pública **Instituto de Ciências Biomédicas, Universidade de São Paulo, São Paulo, SP, Brasil
\end{abstract}

To establish an insecticidal resistance surveillance program, Culex quinquefasciatus mosquitoes from São Paulo, Brazil, were colonized (PIN95 strain) and analyzed for levels of resistance. The PIN95 strain showed low levels of resistance to organophosphates [malathion (3.3-fold), fenitrothion (11.2fold)] and a carbamate [propoxur (3.0-fold)]. We also observed an increase of 7.4 and 9.9 in $a$ and b esterase activities, respectively, when compared with the reference IAL strain. An alteration in the sensitivity of acetylcholinesterase to insecticide inhibition was also found in the PIN95 mosquitoes. The resistant allele $\left(\right.$ Ace. $\left.1^{R}\right)$, however, was found at low frequencies (0.12) and does not play an important role in the described insecticide resistance.

One year later, Cx. quinquefasciatus mosquitoes were collected (PIN96 strain) at the same site and compared to the PIN95 strain. The esterase activity patterns observed for the PIN96 strain were similar to those of the PIN95 mosquitoes. However the occurrence of the Ace. $1^{R}$ allele was statistically higher in the PIN96 strain.

The results show that esterase-based insecticide resistance was established in the PIN95 Cx. quinquefasciatus population and that an acethylcholinesterase based resistant mechanism has been selected for. A continuous monitoring of this phenomenon is fundamental for rational mosquito control and insecticide application programs.

Key words: Culex quinquefasciatus - insecticide resistance - acethylcholinesterase - esterase - control

Culex mosquitoes are important vectors of bancroftian filariasis and a number of other arboviral human diseases. As an important migratory pole, the city of São Paulo constantly attracts people from other regions of Brazil where filariasis is endemic. $C x$. quinquefasciatus is abundant along the Pinheiros River which flows through the southern part of São Paulo, and is a continuous biting nuisance, mostly for those living close to larval habitats, as well as increase the potential for the transmission of parasites and arboviruses.

These data led the local authorities to establish insecticide based mosquito control programs. Malathion and propoxur have been extensively

This work was supported by funds from Superintendência de Controle de Endemias (Sucen), Fundação de Amparo à Pesquisa do Estado de São Paulo (Fapesp) and Conselho Nacional de Desenvolvimento Científico e Tecnológico (CNPq).

${ }^{+}$Corresponding author. Fax: +55-11-229.8292. E-mail: bracco@sucen.sp.gov.br Received 23 April 1998 Accepted 17 August 1998 used since 1980, while diazinon, chlorpyrifos and temephos have been used to a lesser extent (M Dalbon, pers. comm.).

Resistance of $C x$. quinquefasciatus mosquitoes from São Paulo to malathion, fenitrothion and propoxur was recently reported (Bracco et al. 1997). This report presents the log-dosage probit analyses for insecticide resistance and the potential biochemical mechanisms responsible for the insecticide resistance in local mosquito populations.

\section{MATERIALS AND METHODS}

Mosquitoes - Three strains of Cx. quinquefasciatus were used in this study. The susceptible strain (IAL), used as a baseline, has been kept in captivity since 1983 in the Instituto Adolfo Lutz's insectary. It originated from Iguape, a rural area of the State of São Paulo where there is no evidence of organophosphate or carbamate insecticide aplication.

The PIN95 strain was established in 1995. Approximately 3,000 mosquitoes were collected in June 1995 at the margins of the Pinheiros River and transferred to an insectary at the Deptartment of Parasitology, Institute of Biomedical Sciences, 
University of São Paulo. The PIN96 strain was establish one year later, in 1996, with adults captured at the same locality as the PIN95 strain.

These strains have been maintained at $28^{\circ} \mathrm{C}$, $75 \%$ relative humidity and natural photoperiod. Sugar and water were available at all times and the females were routinely bloodfed on immobilized mice.

Bioassays - Unfed adult females of the IAL and PIN95 strains were used for the bioassays as described by World Health Organization (WHO 1981). Twenty-five adult females were exposed to insecticide impregnated papers (purchased from WHO) in standard testing tubes (WHO 1992). They were then transferred to clean tubes where sugar water was provided. The mortality was determined $24 \mathrm{hr}$ after exposure. Control mosquitoes were exposed to papers impregnated only with the insecticide solvent (olive or silicone oil).

Biochemical assays - For the esterase assays, one day old adult females were individually homogenized in $200 \mathrm{ml}$ of $20 \mathrm{mM}$ Na-phosphate buffer, $\mathrm{pH} 7.2$ containing PTC $1 \mathrm{mM}$. The homogenates were centrifuged at $14,000 \mathrm{~g}$ for $10 \mathrm{~min}$ at $4^{\circ} \mathrm{C}$. Two aliquots of $10 \mathrm{ml}$ of supernatant were transferred to different wells of a microtiter plate. Two hundred $\mathrm{ml}$ of a-naphtil acetate or b-naphtil-acetate $(30 \mathrm{mM}$ in $20 \mathrm{mM}$ Na-phosphate buffer, $\mathrm{pH} 7.2$ for both) were added to the wells and the plates incubated at $30^{\circ} \mathrm{C}$. After $30 \mathrm{~min}, 50 \mathrm{ml}$ of Fast blue solution $(45 \mathrm{mg}$ Fast blue B in $9.75 \mathrm{ml}$ of distilled water plus 5.25 $\mathrm{ml}$ of $10 \%$ sodium lauryl sulfate) was added and the absorbances determined at $595 \mathrm{~nm}$ (Hemingway \& Georgiou 1984).

Protein concentration in the supernatants was measured by the BIO-RAD ${ }^{\circledR}$ Coomassie blue protein assay kit in accordance to the manufacturer's instructions, was adapted to microtiter plate volumes and used bovine serum albumin as the standard. The activity unit (U/mg protein) was defined as mMoles of $a$ or $b$ naphtol acetate $/ \mathrm{min} / \mathrm{mg}$ of total protein.
For acetylcholinesterase assays, a single female's head was homogenized in an eppendorf tube containing $250 \mathrm{ml}$ of extraction solution (100 $\mathrm{mM}$ sodium phosphate buffer $\mathrm{pH} 7.0,1 \%$ Triton $\mathrm{X}-100)$. Tubes were centrifuged at $10,000 \mathrm{~g}$ for 1 min and the supernatants used for the assays.

To determine Ace. 1 genotypes, $100 \mathrm{ml}$ of supernatant was placed in two microtiter plate wells. Then, $10 \mathrm{ml}$ of $5 \mathrm{mM}$ propoxur dissolved in acetone were added to one well and $10 \mathrm{ml}$ of acetone added to the other well. The microtiter plates were incubated for $15 \mathrm{~min}$ at room temperature before the addition of $100 \mathrm{ml}$ of the staining solution (25 $\mathrm{mM}$ sodium phosphate buffer $\mathrm{pH} 7.0$ containing $0.2 \mathrm{mM}$ dithiobis 2-nitrobenzoic acid and $0.35 \mathrm{mM}$ of sodium bicarbonate plus $2.5 \mathrm{mM}$ acetylthiocholine - ASCHI). Absorbance at $405 \mathrm{~nm}$ was determined at 3 and 13 min after addition of substrate solution (Bourguet et al. 1997).

\section{RESULTS}

Bioassays - Log-dosage probit-mortality analysis for IAL susceptible and PIN95 resistant strains are shown in Table I. Data obtained for the IAL strain were compatible with the susceptibility of these mosquitoes to the tested insecticides. The PIN95 strain mortalities were compared with those obtained for the susceptible mosquitoes to obtain the resistance ratio. The highest resistance ratio observed was for fenitrothion (11.2 fold) at the $\mathrm{LT}_{50}$ level. The resistance ratios calculated for malathion and propoxur showed lower levels (3.3 and 3.0 respectively).

Esterase activity - The distribution patterns of esterase activities obtained for the IAL, PIN95 and PIN96 strains are shown in the Table II and Figs 1 and 2. The IAL mosquitoes show a distribution pattern in which $100 \%$ of the individuals present esterase activities lower than $300 \mathrm{U} / \mathrm{mg}$ protein. The mosquitoes from PIN95 strain show a higher esterase activity than that of IAL strain. Moreover, the PIN95 population

TABLE I

Culex quinquefasciatus (females) $\mathrm{LT}_{50}$ values with $95 \%$ confidence limits, slope and resistance ratios from bioassays of PIN95 and IAL strains. Resistance ratio were calculated at the $\mathrm{LT}_{50}$ level with reference to the laboratory IAL strain

\begin{tabular}{|c|c|c|c|c|c|c|c|c|c|}
\hline \multirow[t]{2}{*}{ Insecticide } & \multicolumn{4}{|c|}{ IAL } & \multicolumn{5}{|c|}{ PIN95 } \\
\hline & $\mathrm{LT}_{50}$ & $\mathrm{CL}_{95}$ & Slope & $\mathrm{N}$ & $\mathrm{LT}_{50}$ & $\mathrm{CL}_{95}$ & Slope & $\mathrm{N}$ & $\mathrm{RR}_{50}$ \\
\hline Malathion & 9.9 & $8.9-10.7$ & 5.02 & 373 & 32.9 & $26.6-39.5$ & 1.81 & 474 & 3.33 \\
\hline Fenitrothion & 12.2 & $10.8-13.3$ & 4.03 & 395 & 136.3 & $120.6-153.7$ & 2.63 & 472 & 11.20 \\
\hline Propoxur & 66.5 & $62.8-70.7$ & 5.24 & 365 & 200.0 & $159.9-282.8$ & 1.14 & 297 & 3.01 \\
\hline
\end{tabular}

$\mathrm{CL}_{95}$ : confidence limits for $\mathrm{a}=0.05 ; \mathrm{RR}$ : resistance ratio $\left(\mathrm{TL}_{50 \mathrm{PIN} 95} / \mathrm{TL}_{50 \mathrm{IAL}}\right)$; $\mathrm{N}$ : number of exposed. 

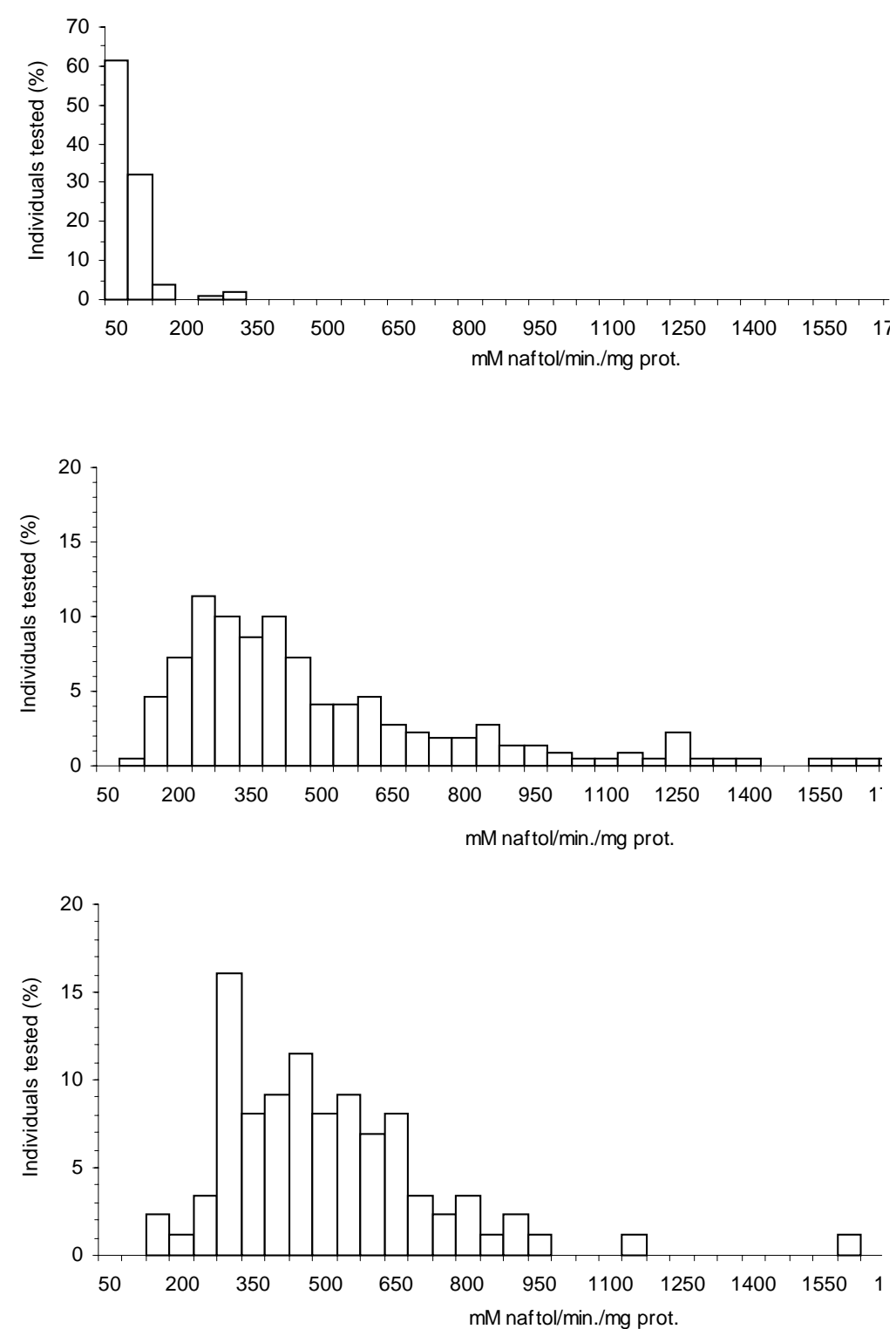

Fig. 1: a esterase activity distribution patterns in females of Culex quinquefasciatus of a) IAL (N=215), b) PIN95 (N=219) and c) PIN96 (N=96) strains.

displays a larger variability (150 to more than $2,000 \mathrm{U} / \mathrm{mg}$ protein). The b-naphthyl acetate was hydrolyzed faster than a-naphthyl acetate by the mosquito homogenates indicating the predominance of esterase $\mathrm{b}$ in PIN95 $C x$. quinquefasciatus mosquitoes. Esterase activities were also determined for the PIN96 mosquitoes. The results indicate a statistically significant higher activity of a-esterase and a lower activity of b-esterase for the PIN96 population, when compared to PIN95 strain $(\mathrm{a}=0.05)$ (Figs 1,2$)$.

Altered AChE gene and genotypes frequencies - The acethylcholinesterase 1 (AChE1) is inhibited by propoxur for all IAL individuals. Altered AChE1 allele $\left(\right.$ Ace. $1^{\mathrm{R}}$ ) was detected in the PIN95 strain with a frequency of 0.12 and in the PIN96 strain in 0.17. Moreover, when the PIN95 and PIN96 Ace.1 frequencies were compared ( $\mathrm{c}^{2}$ test) it was significantly higher in the PIN96 strain population (Table III). 

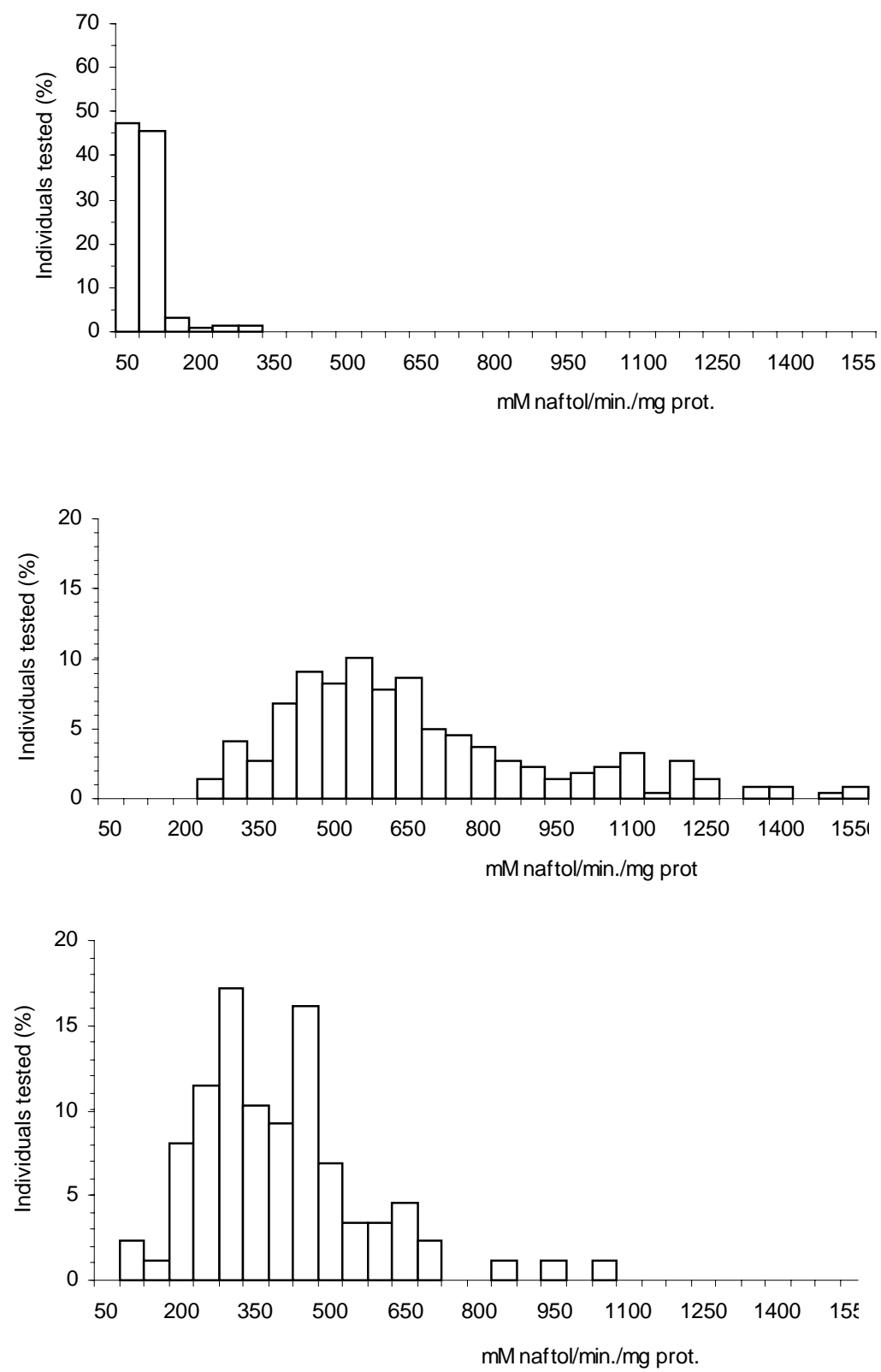

Fig. 2: $b$ esterase activity distribution patterns in females of Culex quinquefasciatus of a) IAL (N=215), b) PIN95 (N=219) and c) PIN96 (N=96) strains.

\section{DISCUSSION}

These data confirm malathion resistance in $C x$. quinquefasciatus mosquitoes population from São Paulo city as previously described by Bracco et al. (1997). The $C x$. quinquefasciatus PIN95 strain is also resistant to fenitrothion, an insecticide that has never been applied by the local mosquito control programs, indicating the occurrence of cross-re- sistance. The intensive and indiscriminate application of several organophosphate insecticides may have resulted in cross resistance to other organophosphates. This hypothesis should be further investigated.

The major insecticide resistance mechanism developed by the studied population seems to be the elevation of esterase activity that was determined to be about 7.4 and 9.9 times higher than 
TABLE II

Culex quinquefasciatus (females) means and standard deviations (s) of a and b esterase activity (U/mg protein) in IAL (N=215), PIN95 (N=220) and PIN96 (N=87) strains

\begin{tabular}{lrrrrrrrr}
\hline Strain & \multicolumn{3}{c}{ a-naphthol production } & & \multicolumn{3}{c}{ b-naphthol production } \\
\cline { 2 - 3 } & Mean & $\mathrm{s}$ & Increase & & Mean & $\mathrm{s}$ & Increase \\
\hline IAL & 55.7 & 39.4 & - & & 57.5 & 39.8 & - \\
PIN95 & 406.9 & 312.2 & 7.4 & & 567.2 & 353.6 & 9.9 \\
PIN96 & 478.2 & 223.3 & 8.7 & & 375.2 & 171.0 & 6.5 \\
\hline
\end{tabular}

$P<0.01$ for a and b esterase with 219 degrees of freedom.

TABLE III

Absolute and relatives frequencies of acetylcholinesterase alleles (Ace.1) in Culex quinquefasciatus females of field collected PIN95 (N=188x2) and PIN96 (N=96x2) strains and the reference strain IAL $(\mathrm{N}=96 \times 2)$

\begin{tabular}{lccc}
\hline Allele & IAL frequencies & PIN95 frequencies & PIN96 frequencies \\
\hline Ace. $1^{\mathrm{S}}$ & $192(1.00)$ & $329(0.875)$ & $159(0.828)$ \\
Ace. $^{\mathrm{R}}$ & $0(0.00)$ & $47(0.125)$ & $33(0.172)$ \\
\hline
\end{tabular}

$\mathrm{C}^{2}=3.86 . P<0.05$ with 1 degree of freedom.

the values determined for the susceptible IAL strain (for a and b esterases respectively). These low values of esterase activity increments and the RR at maximum 11.2-fold agree with previously reported data (Villani et al. 1983, Breeden et al. 1984, Brown 1986, Bisset et al. 1990) that indicated a low elevation of esterase activity may be responsible for the establishment of low levels of resistance to a variety of organophosphates. The significant increase in a esterase activity with the concomitant decrease of the $\mathrm{b}$ esterase, suggest a selection for a esterases as a biochemical mechanism for insecticide resistance.

The Ace. $1^{\mathrm{R}}$ allele was also detected and its proportion increased in the Pinheiros River population. However, while this resistance determining allele is present at a low frequency (0.12 PIN95 and 0.17 PIN96), it is statistically increasing, demonstrating that the resistant Ace. $1^{\mathrm{R}}$ allele is being currently selected for.

The slopes of the log-probit analysis for the PIN95 strain for resistance to the analyzed insecticides demonstrates that it is a heterogeneous population. This heterogeneity is in accordance with the wide distribution of esterase activity and the Ace. $1^{\mathrm{R}}$ frequencies, found in PIN95 and PIN96 mosquitoes (Figs 1, 2; Table III). These data indicate that the insecticide resistance is not fully established in this population.

The low levels of detected resistance may be related to the use of several insecticides by the mosquito control programs during recent years. Eventually, the insecticide resistance in this mosquito population may attain elevated levels to a number of organophosphate compounds. A ratio- nal program of insecticide application supported by continuous surveillance of the population is necessary to avoid the establishment of insecticide resistance. Bracco et al. (1997) have determined the susceptibility of these mosquitoes to pyrethroids. The data obtained suggest that an intervention strategy involving this class of insecticides would be a good choice for the control of $C x$. quinquefasciatus populations in São Paulo.

\section{ACKNOWLEDGMENTS}

To Dr Akemi Suzuki for providing the IAL strain, Dr Moacyr Dalbon for his help collecting mosquitoes that originated the PIN95 and PIN96 strains. To Dr Fernando de Azevedo Corrêa and Dr Eva Pereira Nascimento for their helpful comments on the manuscript, Dr Denis Bourguet for helpful discussions during the establishment of optimal conditions for the $\mathrm{AChE}$ assays and Susana Pessôa Lima for technical assistance.

\section{REFERENCES}

Bisset JA, Rodrigues MM, Diaz C, Ortiz E, Marquetti MC, Hemingway J 1990. The mechanisms of organophosphate and carbamate resistance in Culex quinquefasciatus (Diptera: Culicidae) from Cuba. Bull Entomol Res 80: 245-250.

Bourguet D, Pasteur N, Bisset J, Raymond, M 1997. Determination of Ace.1 genotypes in single mosquitoes: toward an ecumenical biochemical test. Pest Biochem Physiol 55: 122-129.

Breeden GC, Majori G, Breaud TP 1984. Malathion resistance in Culex pipiens in southern Italy. Mosq News 44: 82-83.

Bracco JE, Dalbon M, Marinotti O, Barata JMS 1997. Organophosphorous and carbamate resistance in population of Culex quinquefasciatus (Say,1823) 
from Pinheiros River (São Paulo, Brazil). Rev Saúde Púb 31: 182-183.

Brown AWA 1986. Insecticide resistance in mosquitoes: a pragmatic review. J Am Mosq Control Assoc 2: 123-162.

Hemingway J, Georgiou GP 1984. Baseline esterase levels for anopheline and culicine mosquitoes. Mosq News 44: 33.

Villani F, White GB, Curtis CF, Miles SJ 1983. Inheritance and activity of some esterases associated with organophosphate resistance in mosquitoes of the complex of Culex pipiens L. (Diptera: Culicidae). Bull Entomol Res 73: 153-170.

WHO 1981. Instructions for Determining the Susceptibility or Resistance of Adult Mosquitoes to Organochlorine, Organophosphorous and Carbamate Insecticides, unpublished document, WHO/VBC 81.806, 7 pp.

WHO 1992. Expert Committee on Vector Biology and Control. Vector Resistance to Pesticides, 818 report, unpublished dcument, WHO technical reports series, $63 \mathrm{pp}$ 